\title{
SYNTHESIS AND RELEASE OF ENDORPHINS IN TRIGEMINAL SENSORY NUCLEAR COMPLEX INDUCED BY TOOTH PULP STIMULATION IN THE RAT
}

\author{
Norifumi YONEHARA, Teruo KUDO and Reizo INOKI \\ Department of Pharmacology, Osaka University Dental School, \\ 3-48 Nakanoshima 4 chome, Kita-ku, Osaka 530, Japan
}

Accepted December 2, 1981

The authors have recently shown that electrical stimulation of the tooth pulp caused a significant increase in the content of endorphins (ED) in the Pons- $C_{4}$ area including the spinal trigeminal sensory nucleus in the rat (1). Madden et al. (2) also suggested that the ED system might be engaged by either environmental, sensory, or other physiological events which lead to adaptive change in pain responsiveness. Furthermore, Akil et al. (3) have reported acute stress induced analgesia with concurrent changes in ED levels of central and peripheral systems. These facts suggest that noxious stimulation may produce an increase in the activity of ED-containing neurons and thereby may stimulate $E D$ release from the nerve terminals. In such a condition, it may be expected that D-phenylalanine (DPA), a carboxypeptidase inhibitor (4). enhances the increase of ED levels caused by noxious stimulation, while cycloheximide ( $\mathrm{CHX}$ ) which is an inhibitor of the peptide synthesizing enzyme (5), decreases the changes. In order to verify the possibilities mentioned above, in the present study. influences of both DPA and $\mathrm{CHX}$ on the subcellular ED levels in the Pons- $\mathrm{C}_{4}$ area of the rat were examined with or without stimulation of the tooth pulp. In addition. the analgesic effect of DPA was examined as well

Male Sprague- Dawley rats weighing 200$250 \mathrm{~g}$ were used. Bipolar stimulating electrodes $(0.1 \mathrm{~mm}$ enamel stainiess wire with a tip separation of $1 \mathrm{~mm}$ ) were inserted into the lower incisor tooth pulp of the rats anesthetized with ether. One hr after the operation, the tooth pulp was stimulated by 3 short trains of square waves of $200 \mathrm{~Hz}$, 0.5 msec duration, 5 pulses per train, with a repetition rate of $0.5 \mathrm{sec}$. Immediately after the stimulation, animals were killed by decapitation, and a part of the brain between $5 \mathrm{~mm}$ cranial from the Obex and the $\mathrm{C}_{4}$ level. including the lower Pons and the Subnucleus interporalis and the caudalis of the Trigeminal sensory nucleus, was dissected (Pons $-\mathrm{C}_{4}$ ). The tissue of Pons- $C_{4}$ area was homogenized in $0.32 \mathrm{M}$ sucrose with a Teflon homogenizer and then centrifuged at $100,000 \times \mathrm{g}$ for $1 \mathrm{hr}$. Peilet and supernatant were separated as clearly as possible and then the supernatant was used directly for ED assay. The pellet was resuspended in $10 \mathrm{mM}$ Tris- $\mathrm{HCl}$ buffer $\left(\mathrm{pH} 7.7\right.$ at $25^{\circ} \mathrm{C}$ ) and immersed in a boiling water bath for $15 \mathrm{~min}$ and centrifuged at $100,000 \times \mathrm{g}$ for $1 \mathrm{hr}$, and the supernatant was used for ED assay. The ED levels measured by the radioreceptor assay method were expressed as p moles equivalent to metenkephalin per g tissue. DPA (Wako, Japan) and $\mathrm{CHX}$ (Wako, Japan) were dissolved in saline and injected intraperitoneally (i.p.). Animals were pretreated with DPA $(300 \mathrm{mg} /$ kg) $2 \mathrm{hr}$ before, or $\mathrm{CHX}(50 \mathrm{mg} / \mathrm{kg}) 4 \mathrm{hr}$ before the noxious stimulation was given. Analgesic action of DPA was determined by 


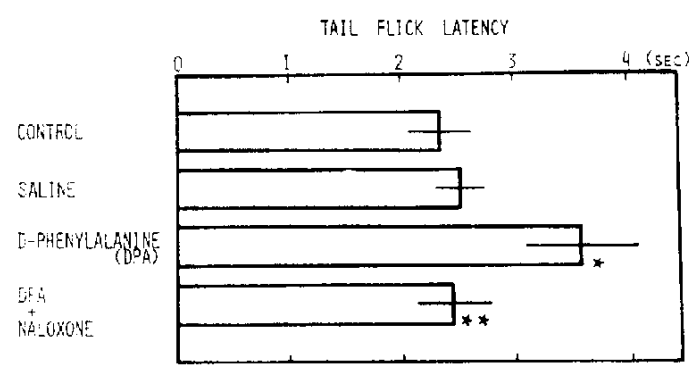

Fig. 1. Effect of DPA on tali-flick latency and its reversal by naloxone $(5 \mathrm{mg} / \mathrm{kg}$. i.p. $30 \mathrm{~min}$ before the tail flick latency test). *significantly different from the control at $P<0.05$. * significantly different from the DPA group at $P<0.05$.

the tail flick method.

Figure 1 shows that DPA (300 $\mathrm{mg} / \mathrm{kg}$. i.p.) causes a significant analgesia and this effect is inhibited by naloxone ( $5 \mathrm{mg} / \mathrm{kg}$, i.p.). Ehrenpreis et al. $(6,7)$ have shown that DPA which blocked a carboxypeptidase, one of the ED degradation enzymes, induced analgesia in humans and mice. Our present results on rats coincided with their findings. On the other hand, tooth pulp stimulation produced a significantly increased level of ED in both the pellet and the supernatant fractions from the Pons $-\mathrm{C}_{4}$ area (Fig. 2). In addition, treatment with DPA alone produced a significant increase in ED levels in the supernatant fraction. but not in the pellet fraction without stimulation, suggesting that DPA-sensitive ED degradation enzymes are contained in an extracellular space. However, an increased level of ED induced by tooth pulp stimulation was not significantly changed by the prior administration of DPA in both fractions. This fact suggests that some peptidases different from DPAsensitive carboxypeptidase are also involved in the inactivation process of ED peptides. In this connection, four peptidases have been recently identified as being responsible for enkephalins degradation $(8-11)$. In contrast to DPA. CHX punduced a $20 \cdots 25 \%$ decrease in ED levels of both the pellet and

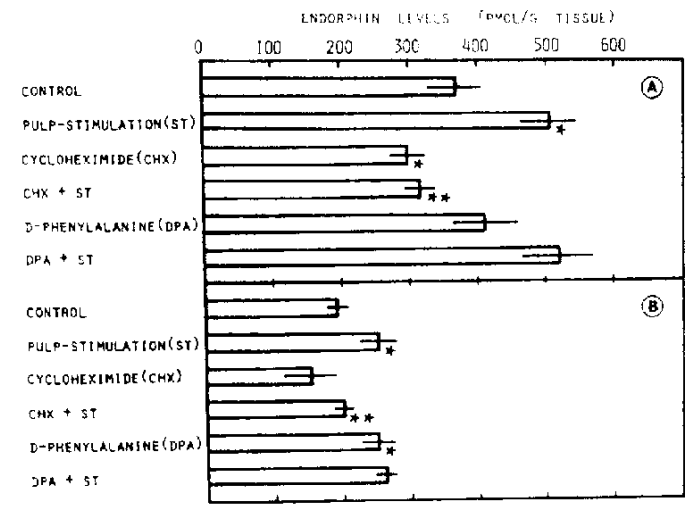

Fig. 2. Effect of DPA $(300 \mathrm{mg} / \mathrm{kg}$, i.p. $2 \mathrm{hr}$ before tooth pulp stimulation $)$ and $C H X(50 \mathrm{mg} / \mathrm{kg}$, i.p. $4 \mathrm{hr}$ before tooth pulp stimulation) on endorphin levels in the subcelluiar fractions of the Pons $-\mathrm{C}_{4}$ area with and without stimulation of the tooth pulp. (A) pellet fraction, (B) supernatant fraction. Each column represents the mean $\pm S D$ of 10 experiments. * significantly different from the control at $P<0.05$. * significantly different from the ST group at $P<0,05$.

the supernatant fractions without stimulation. The differences between controland $\mathrm{CHX}$ groups were statistically significant in the pellet fraction, but not in the supernatant fraction, suggesting that $\mathrm{CHX}$-sensitive $\mathrm{ED}$ synthetizing enzymes are contained in the pellet fraction. Furthermore, an increased level of ED in both fractions induced by tooth pulp stimulation was significantly inhibited by the prior administration of $\mathrm{CHX}$. These results suggest that noxious stimulation results in an enhanced synthesis of ED by a $\mathrm{CHX}$-sensitive process in the pellet fraction which is followed by a release of ED from a component of the pellet fraction into an extracellular space. With respect to a change of ED level in brain. Madden et al. (2, 3) reported that opioid peptides were significantly elevated after an intermittent footshock. These results suggest that the ED levels of the brain may be modulated by stressful stimuli as well as noxious stimuli. However. it is well known that couth pull stimulation evokes mainly a painful sensation 
in human and that pseudo-affective behaviors result from such stimulation in animals (1215). Therefore, it may be considered in the present study that in the Pons- $\mathrm{C}_{4}$ area including the trigeminal neurons excited by tooth pulp stimulation, the changes of ED levels induced by the tooth pulp stimulation mainly correspond to the noxious stimulation.

In conclusion, our present observations suggest that ED can be synthesized and released in the Pons $-\mathrm{C}_{4}$ area including the spinal trigeminal sensory nucleus of the rat in response to depolarization caused by tooth pulp stimulation. These behaviors of ED are characteristic of a number of neurotransmitters in central nervous systems and support the hypothesis that ED plays a role as a neurotransmitter involved in pain transmission.

\section{REFERENCES}

1) Inoki, R., Iwatsubo, K., Kudo, T., Yonehara, N.,

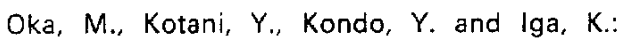
Endorphin levels in the rat brain after the tooth pulp stimulation. In Endogenous and Exogenous Opiate Agonists and Antagonists, Edited by Way, E.L., p. 333-336. Pergamon Press, New York (1980)

2) Madden, J., Akil, H., Patrick, R.L. and Barchas, J.D.: Stress-induced parallel changes in central opioid levels and pain responsiveness in the rat. Nature 265, 358-360 (1977)

3) Akil, H., Madden, J., Patrick, R.L. and Barchas, J.D.: Stress-induced increase in endogenous opiate peptides: Concurrent analgesia and its partial reversal by naloxone. In Opiates and Endogenous Opioid Peptides, Edited by Kosterlitz, H.W., p. 63-70, Elsevier/NorthHolland, New York (1976)

4) Delange, R.J. and Smith, E.L.: Leucine aminopeptidase and other $\mathrm{N}$-terminal exopeptidases. In The Enzyme. Edited by Boyer. F.D.. Vol. 3. p. 81-119. Academic Press, New York (1971)
5) Harris, C., Reddy, J. and Svoboda, D.: The effect of cycloheximide on ribonucleic acid and protein synthesis in rat liver. Biochem. Pharmacol. 18, 951-954 (1969)

6) Ehrenpreis, S., Comaty, J.E. and Myles, S.B.: Naloxone reversible analgesia produced by $D$. phenylalanine in mice. In Characteristics and Function of Opioids. Edited by van Ree. J.M. and Terenius, L., p. 417-418, Elsevier/NorthHolland. New York (1978)

7) Ehrenpreis, S., Balazot, R.C., Myles, S., Advocate C. and Comaty, J.E.: Further studies on the analgesic activity of D-phenylalanine (DPA) in mice and humans. In Endogenous and Exogenous Opiate Agonists and Antagonists, Edited by Way, E.L., p. 379-382. Pergamon Press, New York (1980)

8) Marks, N., Grynbaum, A. and Neidle, A.: On the degradation of enkephalins and endorphins by rat and mouse brain extracts. Biochem. biophys. Res. Commun. 74, 1552-1559 (1977)

9) Malfroy, B., Swerts, J.P., Guyon, A., Roques, B.P. and Schwartz, J.C.: High-affinity enkephalin-degrading peptidase in brain is increased after morphine. Nature 276, 523526 (1978)

10) Gorenstein, G. and Snyder, S.H.: Two distinct enkephalinase: solubilization, partial purification and separation from angiotensin converting enzyme. Life Sci. 25, 2065-2070 (1979)

12) Brookhart, J.M., Livingston, W.K. and Haugen, F.P.: Functional characteristics of afferent fibers from tooth pulp of cat. J. Neurophysiol. 16. 634-642 (1953)

13) Matthews, B., Baxter, J. and Watts, S.: Sensory and reflex responses to tooth pulp stimulation in man. Brain Res. 113, 83-94 (1976)

14) Azerad, J. and Woda, A.: Sensation evoked by bipolar intrapulpal stimulation in man. Pain 4, 145-152 (1977)

15) Sessle, B.J.: Is the tooth pulp a "pure" source of noxious input? in Advances in Pain Research and Therapy. Edited by Bonica, J.J., Liebeskind, J.C. and Albe-Fessard, D.G., Vol. 3, p. 245260. Raven Press. New York (1979) 